\title{
Efficient Management of Aircraft Taxiing Phase by Adjusting Speed Through Conflict-free Routes
}

\author{
Otmane Idrissi *, Bikir Abdelmounaime, Khalifa Mansouri \\ Laboratory Signals, distributed systems, and artificial intelligence, Higher normal school of technical education ENSET, University \\ Hassan II Mohammedia, Morocco
}

\begin{abstract}
Air traffic congestion is considered to be the main problem in air traffic management. It represents a real handicap in the current rising air traffic flows without a corresponding enhancement in airport infrastructure. This issue leads to more workloads for air traffic controllers, air stakeholders and other airport operations. The following paper aims to minimize the departure aircraft taxiing time in the movement area. This duration can be affected by several factors such as routing, taxiing speed, holding while taxiing ... etc. In this work, we are going to solve the previous problem by using a tactical planning tool: it consists on assigning efficient and nonstop routes to the scheduled traffic on departure. This tool, using a real-time algorithm, will detect in advance routing conflicts and solve them before aircraft leave stands and approach the hotspots in taxing network. Furthermore, the proposed method will optimize the use of the available ground network by acting on the taxiing speed in order to reduce departures' delays, fuel consumption and gas emissions.
\end{abstract}

Keywords Air traffic management, Ground movement, Predicting taxi time, Conflict-free taxiing routes, Air traffic optimization, Airport surface operation, aircraft taxiing speed.

AMS 2010 subject classifications 90B50, 90C59, 90B06

DOI: $10.19139 /$ soic-2310-5070-1162

\section{Introduction}

The air traffic volume has made a new record in the year of 2018 with an increase of 3,8 in air transportation movements. Statistics show that the summer months were particularly the busiest and had more delays. These delays were nevertheless eased via specific routing measures put in place by the Network Managers, making the best use of all available capacity in the network as revealed by EUROCONTROL [1]. The same report was established at the International Air Transport Association IATA when it comes to the continuous expansion of air transportation. Its growth rate is around 3,5 compound annual rate. Forecasting suggest that passengers' numbers could reach 8,2 billion by the year 2037 leading to a doubling in the passengers' numbers from today's level [2]. The first problem to be solved is the ground movement of aircraft at airports. It represents the beginning of the all following congestion problems, and leads to increased flight delays and costs. On another hand, aircraft engines are inefficient at low speed on the ground. Which makes a large contribution to the running cost and aircraft emissions' by wasting more fuel (while waiting in holding areas, stopping and restarting taxiing many times during ground movement for separation). Most previous works have discussed two major ground issues: allocating the shortest route, and improving taxiing time prediction. This work aims to avoid holding and braking action during the taxiing phase. It is going to apply optimized speed adjustments, (which can be controlled all along the taxiing phase) and assist air traffic controllers with a decision support tool. This tool is allocating efficient and conflict-free taxiing

\footnotetext{
${ }^{*}$ Correspondence to: Otmane Idrissi (Email: iodrimane@ gmail.com). ENSET laboratoire SSDIA UH2M BP 159 Mohammedia Principale.
} Adresse : Boulevard Hassan II Mohammedia. (28830).

ISSN 2310-5070 (online) ISSN 2311-004X (print)

Copyright (c) 2022 International Academic Press 
routes, in order to reduce congestion, fuel consumption (space befor fuel), emissions and predict more accurately the taxiing time. It also optimizes the planned departure routes by taking into account several evaluation functions and different aspects of departure management in order to enhance capacity and efficiency.

\section{Related work}

\subsection{Ground movement problem}

Managing efficiently the ground movements is the main key to optimize the air traffic flow and the use of the air network. It has a significant impact on other important airport operations such as runway sequencing and gate assignment. [3] Redefined the taxiway model from a pure graph of nodes and edges to a zone-based partition of the taxiways. [4] Addressed the ground movement problem as a network congestion control problem, making use of a probabilistic model based on Erlang random variables for taxi-out times at Boston Logan Airport. [5] Considered the similarity of ground movement to road traffic flows, proposing a modeling approach based on the cell transmission model for simulating the evolution of flow and congestion on taxiways. [6] Proposed a Management of speeds, time slots, landing runway, and pushback delay to optimize taxi times. The authors in [7] and [8] managed the gate/stand allocations to optimize Ground Movement. The papers [9] and [10] used the shortest path algorithm and heuristic search algorithms (such as genetic algorithms) and they selected an appropriate route and wait points for each aircraft. [11] Showed that arriving aircraft can indeed produce a lot of delay to overall taxi movements, and they noted the importance of having an accurate model for the pushback process. The work [12] Described the QPPTW algorithm, an adaptation of Dijkstra's shortest path algorithm that accounts for the movements of previously-allocated aircraft rather than optimization of routes. [13] used genetic algorithms to evolve the routes rather than choosing predefined ones. The papers [14], [15], [16] and [17] formulated Ground Movement as a mixed-integer linear programming problem.

\subsection{Estimating taxiing time}

In paper [17] the authors compared several modeling approaches and found that fuzzy approaches are the most accurate modeling to yield the problem. In [18] They used a dynamic programming approach combined with a model drawing on taxi times, to determine the optimal pushback times at Logan International Airport. Mitigating the effect of delays in taxing phase. The work [19] developed a probability distribution function to model taxi times for JFK Airport. [20] Used a regression model to estimate taxi times at Newark Liberty Airport and the paper [21] demonstrated a log-linear regression analysis to estimate taxi time.

\subsection{Uncertainties of taxiing time}

An accurate taxi time forecast is useful to various air stakeholders. This allows a better certainty in taxiing prediction and provides important forecasts for all parties in the airport. It will be increasingly important to have precise control of the aircraft on the ground through an advanced decision support system to reduce conflicts and minimize delays. [22] Proposed the use of time margins around aircraft trajectories. [23] Gave a comprehensive assessment of the predictability impacts of airport surface automation. A wide range of the impacts was considered, which included variability in taxi-out time. The paper [24] Reflected the impact of uncertainty on ground movement using a simulation with speed variations in profile at Detroit International Airport. Studying Variations in taxi speeds showed significant increases in ground delay for departures. The works [25] and [26] reflected the strong impact of taxi time uncertainty on the airport's efficiency.

\section{Problem description and proposed solution}

Jet-engines operate optimally at cruising in the air, but they are inefficient while propelling an aircraft at low speed on the ground [27]. As mentioned above, previous works in ground movement has tackled two major axes: taxiing 
time problem by allocating the shortest route, and the prediction of taxiing time. This work aims to optimize ground movement management. It consists on allocating efficient and conflict-free routes to avoid waiting in holding areas by applying optimum taxiing speed. In this paper, we are going to start by handling the apron conflicts, then tackle the hotspots management and finally minimize the delay by applying specific taxiing speed.

\subsection{Management of conflicts in the Apron}

First of all, we will Start by managing apron's conflicts. As shown in Figure 1 the stands in orange will be condemned once the blue aircraft start taxiing. Which means that the other aircraft occupying these stands cannot taxi or push back till the blue aircraft clears the way. Using Table 1 as data base accurately reflects the situation of all stands:

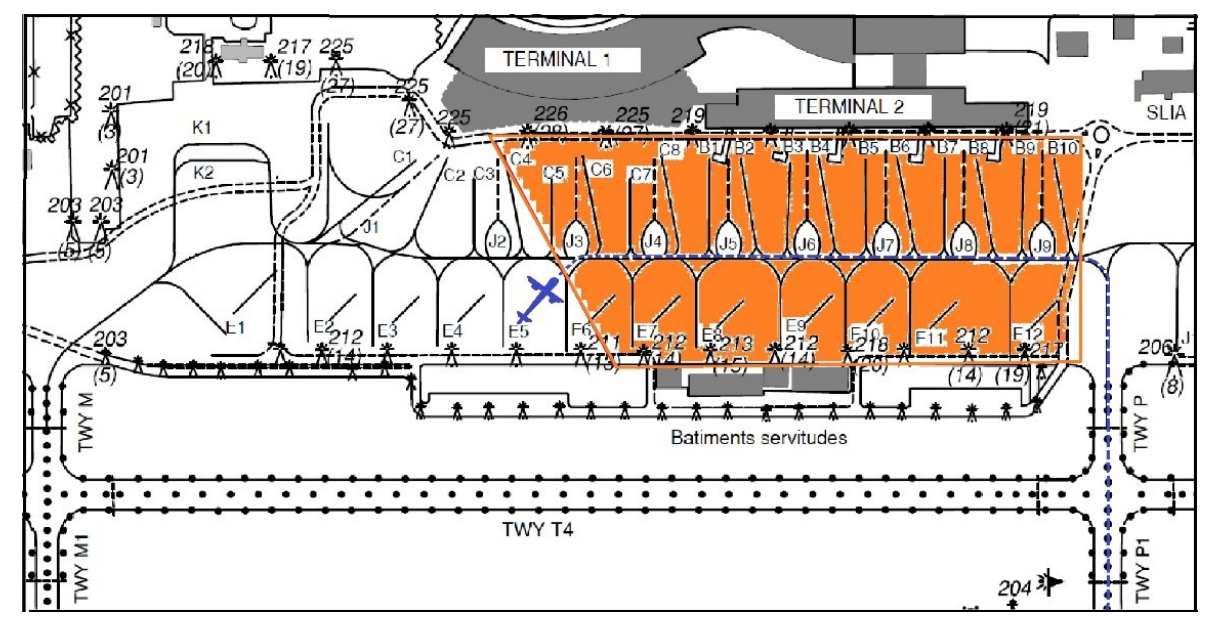

Figure 1. Stands map (example: part of Mohammed V International Airport) From AIP Morocco.

Modelization of the variables in the database:

$A_{i}$ is the aircraft(i) at the stand(i) $P_{i}, t b_{i}(K)$ is the Estimated lock time of the stand $P_{i}$ by the $K^{t h}$ aircraft. $t d_{i}(K)$ is the Estimated deadlock of $P_{i}$ by the $K^{t h}$ aircraft. $E T D(i)$ is the Estimated departure time of $A_{i}$. EOBT $(i)$ is the estimated out of block time of $A_{i}$, according to $E T D(i)$ and taxi time as estimated value published by local authority. $T x T(i)$ is the Calculated taxi time according to the type of aircraft $A_{i}$ and stand Pi. Let $C T x T(i)$ be the calculated taxi out of the block time of $A_{i}$ from the stand Pi, Time for "( $\mathrm{Pi}$ ) forme non mathématique" aircraft $A_{i}$ to clear the stand $P_{i}$ is: $t d_{i}(K)=C T x T(i)$. If $P_{k}$ is blocked by $A_{i}$ so $t d_{i}(K)>C T x T(i)$. The aircraft $A_{i}$ locks the stand(k) from the time $t b_{i}(K)$ until the time $t d_{i}(K)$ and the nearest available time of the stand(k) is: from $t d_{i}(K)$ until $t b_{i+1}(K)$. 
Table 1. Condemned stands.

\begin{tabular}{c|cccccccc}
\hline Stand & $P_{1}$ & $P_{2}$ & $P_{3}$ & $P_{4}$ & $P_{i}$ & $P_{i+1}$ &.. & $P_{n}$ \\
\hline Condemned $/ \mathrm{n}$ & 0 & 1 & 1 & 0 & $1 / 0$ & $1 / 0$ & $\ldots$ & $1 / 0$ \\
\hline Lock time(1) & $t b_{1}(1)$ & $t b_{2}(1)$ & $t b_{3}(1)$ & $t b_{4}(1)$ & $t b_{i}(1)$ & $t b_{i+1}(1)$ &.. & $t b_{n}(1)$ \\
\hline Deadlock time (1) & $t d_{1}(1)$ & $t d_{2}(1)$ & $t d_{3}(1)$ & $t d_{4}(1)$ & $t d_{i}(1)$ & $t d_{i+1}(1)$ &.. & $t d_{n}(1)$ \\
\hline Lock time (2) & $t b_{1}(2)$ & $t b_{2}(2)$ & $t b_{3}(2)$ & $t b_{4}(2)$ & $t b_{i}(2)$ & $t b_{i+1}(2)$ &.. & $t b_{n}(2)$ \\
\hline Deadlock time (2) & $t d_{1}(2)$ & $t d_{2}(2)$ & $t d_{3}(2)$ & $t d_{4}(2)$ & $t d_{i}(2)$ & $t d_{i+1}(2)$ &.. & $t d_{n}(2)$ \\
\hline$\ldots$ & $\ldots$ & $\ldots$ & $\ldots$ & $\ldots$ & $\ldots$ & $\ldots$ & $\ldots$ & \\
\hline
\end{tabular}

\subsection{Management of conflicts at the hotspots}

In this section we will tackle hotspots management as shown in Figure 2. Using Table 2 as data base accurately reflects the situation of all hotspots.

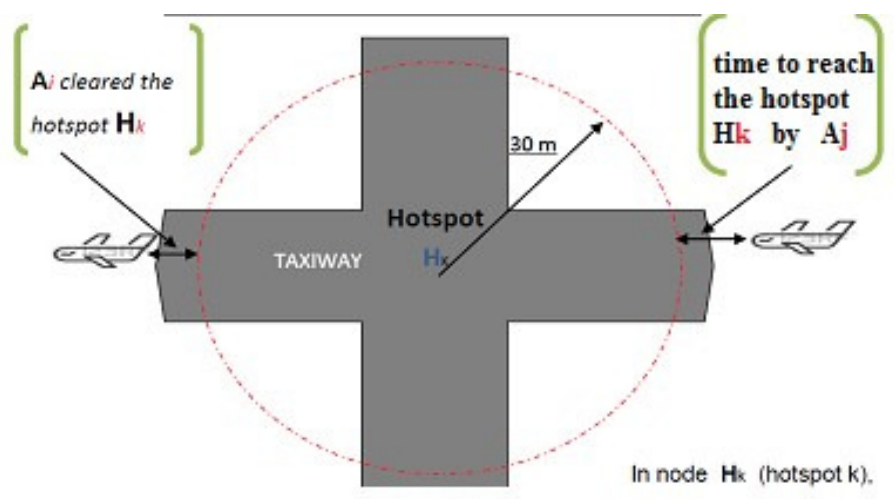

Figure 2. Conflict management at hotspots. 
Table 2. Condemned stands.

\begin{tabular}{c|ccccccccc}
\hline Hotspot & $H_{1}$ & $H_{2}$ & $H_{3}$ & $H_{4}$ & $H_{i}$ & $H_{i+1}$ & $\ldots$ & $H_{n}$ \\
\hline Time for $A_{1}$ to enter the Hotspot $H_{i}$ & $E_{1,1}$ & $E_{1,2}$ & $E_{1,3}$ & $E_{1,4}$ & $E_{1, i}$ & $E_{1, i+1}$ & $\ldots$ & $E_{1, n}$ \\
\hline Time for $A_{1}$ to clear the Hotspot $H_{i}$ & $C_{1,1}$ & $C_{1,2}$ & $C_{1,3}$ & $C_{1,4}$ & $C_{1, i}$ & $C_{1, i+1}$ & $\ldots$ & $C_{1, n}$ \\
\hline Time for $A_{2}$ to enter the Hotspot $H_{i}$ & $E_{2,1}$ & $E_{2,2}$ & $E_{2,3}$ & $E_{2,4}$ & $E_{2, i}$ & $E_{2, i+1}$ & $\ldots$ & $E_{2, n}$ \\
\hline Time for $A_{2}$ to clear the Hotspot $H_{i}$ & $C_{2,1}$ & $C_{2,2}$ & $C_{2,3}$ & $C_{2,4}$ & $C_{2, i}$ & $C_{2, i+1}$ & $\ldots$ & $C_{2, n}$ \\
\hline$\ldots$ & $\ldots$ & $\ldots$ & $\ldots$ & $\ldots$ & $\ldots$ & $\ldots$ & $\ldots$ & \\
\hline
\end{tabular}

The aircraft $A_{i}$ occupies the hotspot(k) from the time $E_{i, k}$ until the time $C_{i, k}$ and the nearest available time to cross the hotspot(k) is from the time $E_{i, k}$ until the time $C_{i+1, k}$.

\section{Calculating taxiing out time of the block Ctxt}

\subsection{Calculating Ctxt according to hotspots and condemned stands}

\section{Begin}

for each i;

$A_{i}$ aircraft in the $P_{i}$ stand with $E T D_{i}$;

Generate route;

Generate the list of hotspots in the route;

Generate the list of condemned stands;

Calculate $T x t_{i} ; / *$ using the type of aircraft and position of the stand

$C T x T_{i}=E T D_{i}-T x T_{i} ;$ /* Calculate $C T x T_{i}$, taxiing Time to reach holding point at $E T D_{i}$

while $k<M / *$ Calculate $r_{i}$

if $t d_{k}<C T x T_{i}$ and $t b_{k+1}>C T x T_{i}$

$r_{i}=0 / *$ No delay expected

if $t d_{k}>C T x T_{i}$

$r_{i}=t d_{k} / *$ Correction of $C T x T_{i}$

End while

$C T x T_{i}=r_{i} ; / *$ update $C T x T_{i}$

for $k=1$ to $N$ do; /* calculate $W i$ time to wait in hotspot $\mathrm{i}$

calculate the $E_{i, k} ; / *$ Time to reach hotspot $\mathrm{k}$

calculate the nearest $C_{i, k} / *$ Time for $A_{i}$ to clear the hotspot k; $/ * A_{j}$ the precedent aircraft passing by the hotspot if $E_{i, k}-C_{j, k}>0$

$W_{i}=0 ; / *$ No delay expected

Else

$W_{i}=E_{i, k}-C_{j, k} / *$ Delay added to $C T x T_{i}$

End if;

$C T x T_{i}=C T x T_{i}+W_{i}$;

$k=k+1$;

end for; 
update condemned stands then conflict slots; $/ *$ Check the impact of stands then the hotspots situation

end for;

end.

\subsection{Updating aircraft position}

After Calculating $C T x T_{i}$, we get a new estimate out of the block time and estimated total taxi time, to make this data more accurate we need to update the position of each aircraft by comparing the real position with the estimated one. let $A_{i}$ be the aircraft(i) at the real position $\Pi(i)$ with estimated position $\Omega(i)$, and $\Lambda(i)$ is the estimated time to reach the position $\Omega(i)$ from $\Pi(i)$;

begin

for $t=0$

for each $i$;

Calculate $\Pi(i)$; Calculate $\Omega(i)$; calculate $\Lambda(i)$;

If $\Lambda(i)>0$

$C T x T_{i}=C T x T_{i}+\Lambda(i)$

End if

end for

$t=t+\Delta(t) / * \Delta(t)=60 s$ is the needed time to update the situation

end for

update condemned stands;

update conflict slots;

end.

\subsection{The saved time by applying Ctxt}

As shown in Table 3, applying a case study of this method in real traffic, we noticed that a delay of around 16 minutes was accumulated by only 10 of the 274 aircraft scheduled for the same day, so the application of the "CTxT" Method saves a significant time and improves taxiing time prediction as it is proved by this experiment.

Table 3. Example of the situation from Mohammed V Airport

\begin{tabular}{|c|c|c|c|c|c|c|c|}
\hline TP & Std & Fly & Act & Stp Nm & Y/CTxT & N/CTxT & Delay \\
\hline A320 & E06 & 30335 & $06: 00$ & 4 & $430 \mathrm{~s}$ & $250 \mathrm{~s}$ & $180 \mathrm{~s}$ \\
\hline A320 & B14 & 3 O457 & $06: 50$ & 3 & $330 \mathrm{~s}$ & $200 \mathrm{~s}$ & $130 \mathrm{~s}$ \\
\hline B738 & D03 & AT778 & $07: 30$ & 2 & $220 \mathrm{~s}$ & $130 \mathrm{~s}$ & $90 \mathrm{~s}$ \\
\hline A320 & E02 & AF1497 & $07: 40$ & 4 & $460 \mathrm{~s}$ & $280 \mathrm{~s}$ & $180 \mathrm{~s}$ \\
\hline A320 & D06 & AT728 & $07: 40$ & 2 & $210 \mathrm{~s}$ & $120 \mathrm{~s}$ & $90 \mathrm{~s}$ \\
\hline B738 & C03 & AT946 & $07: 45$ & 3 & $50 \mathrm{~s}$ & $300 \mathrm{~s}$ & $200 \mathrm{~s}$ \\
\hline B788 & J11 & AT760 & $08: 00$ & 3 & $390 \mathrm{~s}$ & $300 \mathrm{~s}$ & $90 \mathrm{~s}$ \\
\hline B738 & E07 & AT1634 & $09: 25$ & 4 & $440 \mathrm{~s}$ & $240 \mathrm{~s}$ & $200 \mathrm{~s}$ \\
\hline B789 & J09 & EY612 & $09: 50$ & 4 & $440 \mathrm{~s}$ & $300 \mathrm{~s}$ & $140 \mathrm{~s}$ \\
\hline E190 & B12 & AT411 & $10: 10$ & 4 & $340 \mathrm{~s}$ & $250 \mathrm{~s}$ & $90 \mathrm{~s}$ \\
\hline
\end{tabular}

Std: stand

Fly: flight

Act: Activation time

Stp Nm: number of stops expected 
Y/CTxT: Estimated taxiing time Using CTxT

N/CTxT :Estimated taxiing time without Using CTxT

\section{Predict the taxiing time and minimize the burned fuel}

\subsection{The importance of taxiing time prediction and its uncertainty}

When an aircraft arrives at the $\Pi(i)$ position at a different time than expected, it can cause conflicts with other aircraft leading to delays. Therefore, predicting taxi time is an essential process to optimize ground movements. [25] Demonstrated a log-linear regression analysis to estimate taxi time. And to cope with the uncertainty of taxi time, [28] used an increased temporal separation between aircraft. In [25]; [26] authors reflect the strong impact of taxi time uncertainty on the airport's efficiency. [15] Showed that Uncertainty in taxi times can be explicitly recognized and tackled, they Suggest that punctuality figures should be adjusted to use take-off times rather than push-back times, and [27] showed that Adaptive Mamdani fuzzy rule-based system, generating multiple routes for different levels of uncertainty, reduced delays by 10-20\% over the original QPPTW, he proved that at Manchester Airport, And [29] at Zurich Airport. [22] Used a simulation to explore the effect that the size of buffers around taxiing aircraft has upon throughput and robustness, finding that taxi time uncertainty is a major factor preventing the optimal use of the taxiways and runways.

\subsection{Taxiing speed effect in ground movement optimization}

[9] Tried to predict taxi time by defining initially taxi speed, such uncertainty has been modeled as a fixed percentage of the initially defined taxi speed. [24] Reflected the impact of uncertainty on Ground Movement using a simulation with speed variations in profile, at Detroit International Airport. They found that variations in taxi speeds resulted in significant increases in ground delay for departures. It is necessary to take into account the problem of speed profile optimizing, which is not saving time only but also fuel and reducing airport emissions. One of the aims of this work is Calculating $C T x T$ for each aircraft to Improve the Prediction of taxi time on Ground Movement by maintaining a constant speed as long as possible and avoid deceleration and braking actions all along the taxiing route as shown in Figure 3:

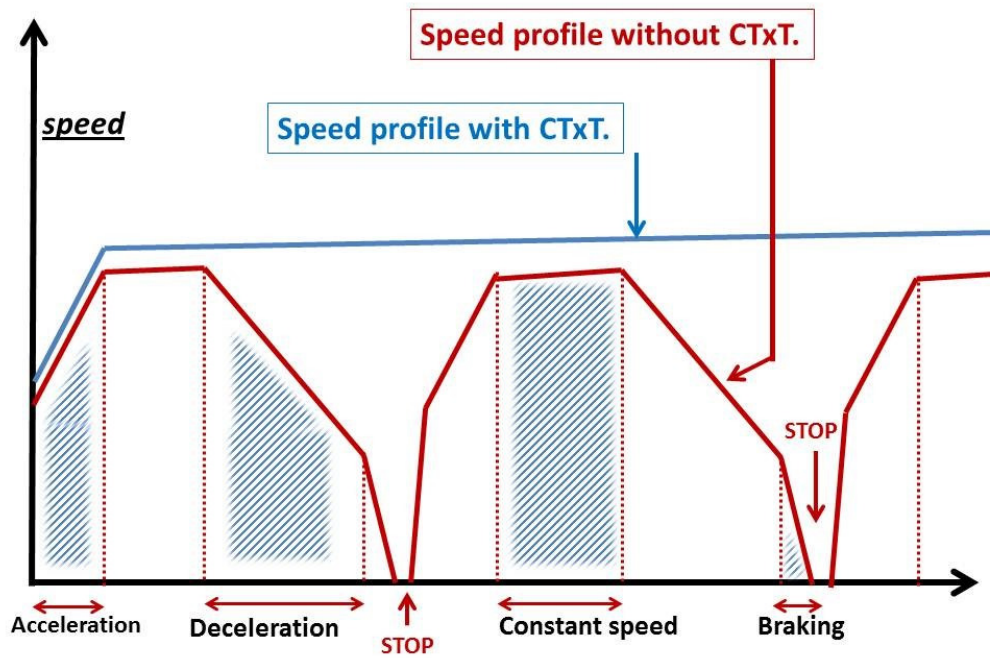

Figure 3. Speed profile on a straight segment passing by 2 hotspots with and without CTxT. 


\section{Acting on taxiing speed}

By Applying our method, we can attribute a taxiing route without any stop or hold during all the taxiing phase. The aircraft can keep a constant taxiing speed during all the taxiing phases, as shown in Figure 3, which able us to apply a change to the taxiing speed value to minimize the taxiing cost. It will have also other advantages like operational safety, efficiency, and predictability, towards optimal use of infrastructure, even with higher and more complicated traffic expected.

\subsection{Taxiing speed adjustment TSA}

During the taxiing phase, the main key is to ensure continuous taxiing and maintaining constant speed as long as possible is the management of hot spots, as mentioned in point III-B, next part of our work is to enhance the use of the airport network by acting on the taxiing speed to minimize the delay caused by the hotspot conflicts.

To apply our method, we calculate an estimated time of each aircraft to leave the stand and start taxiing, this CTXT is known as a delay received from the air traffic management service ATS, the next step in our work is to minimize the generated delay by attributing specific taxiing speed respecting all constraints.

\subsection{Modelization of the proposed model}

Air traffic management is a task that requires proactive decision making by air traffic controllers, and the main used tool is the estimated time and duration of each execution part in all phases, that's why we choose a concept based on Time rather than distance, and by acting on the speed we get a clear set of estimated times and duration expected in all segments of the taxiing route in a network of segments and nodes as illustrated in Figure 4:

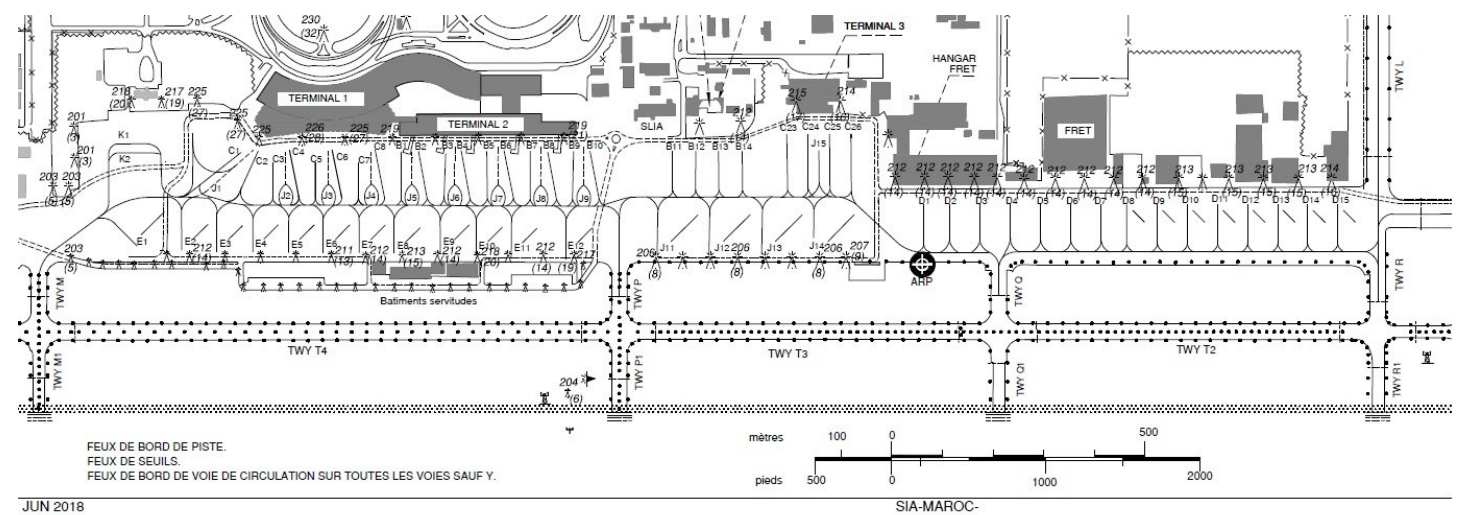

Figure 4. Mohammed V airport taxiing chart.

Let $V_{i}$ be the taxiing speed of the aircraft $A_{i}$;

$d_{i}$ the crossed distance by $A_{i}$ from the stand $S_{i}$ to reach the hotspot $\mathrm{H}$.

$f_{i}\left(d_{i}\right)$ is the needed time to cross the distance $d_{i}$ between stand $S_{i}$ and the hotspot $\mathrm{H}$.

$$
f_{i}\left(d_{i}\right)=\frac{d_{i}}{V_{i}}
$$

$r_{i}$ is the generated delay of the aircraft $A_{i}$ due to conflicts in route.

So the multi-objective minimizing problem to solve is:

$$
\min \sum_{i=2}^{n}\left|f_{i}\left(d_{i}\right)-r_{i}\right|
$$


The problem was solved by the meta heuristic method: Partial Swarm Optimization.

$t x_{i}$ is the estimated time of aircraft $A_{i}$ to reach the first holding point $H_{1}$, The aircraft $A_{i}$ may cross the hotspot from $t x_{i-1}+1 \mathrm{~min}$, so the problem is minimizing $t x_{i}$ under the following condition: $t x_{i} \geq t x_{i-1}+1 \mathrm{~min}$.

\subsection{Simulation}

We're going to simulate our algorithm in a defined period, generating a random set of: activation time; type of aircraft $\left(A_{i}\right)$; stand $\left(P_{i}\right)$. We calculate the new speed based on the following formula:

$$
\begin{gathered}
V_{k+1}=c_{1} V_{k}+c_{2}\left(\text { best }_{p}-X_{k}\right)+c_{3}\left(\text { best }_{v}-X_{k}\right) \\
X_{k+1}=X_{k}+V_{k+1}
\end{gathered}
$$

With:

$X_{k}$ is the position of the particle at the $k$ iteration.

$V_{k}$ is the speed of the particle at the $\mathrm{k}$ iteration.

best $_{p}$ is the best position of the particle.

best $_{v}$ is the best position of the particle vicinity at the $\mathrm{k}$ iteration.

$c_{1}$ is a coefficient during iterations. $c_{2}$ et $c_{3}$ are coefficients randomly generated at each iteration.

\section{Algorithms and comparative study}

\subsection{Applying adjustments on taxiing speed}

Speed modification is a useful technique during the taxiing phases with the instruction: slow down or speed up, and it can go up to $20 \%$ applied to the $V_{i}$ the stored taxiing speeds in the database according to the type of aircraft. After Calculating $C T x T(i)$, we get a new estimate out of the block time and estimated total taxi time, afterwards, we apply the speed adjustments, we proceed by optimization to calculate $\left(a_{i}\right)$ which is the predicted percentage changes in speed, so the aircraft $A_{2}$ can cross the conflicted hot spot at test $v_{2}$ with:

test $v_{2} \geq$ testv $_{1}+1 \mathrm{~min}$; and so on for the rest of $A_{i}$, with:

$$
\text { testv } v_{i} \geq \text { testv }_{i-1}+1 \text { min }
$$

finally, we calculate:

$$
R v_{i}=t e s t v_{i}-t p(i)
$$

$\operatorname{tp}(i)$ is the estimated cross time of hotspot without conflict resolution; $R v_{i}$ is the delay of $A_{i}$. The percentages' computation of $A_{i}$, is a minimization problem which formulated as follows:

$$
\min \left|t v_{i}\left(a_{i}\right)-t e s t v_{i}\right|
$$

u:c: $-20 \% \leq a_{i} \leq 20 \%$ with:

$$
\begin{array}{r}
t v_{i}\left(a_{i}\right)=\frac{d_{i}}{\left(1+a_{i}\right) V_{i}} \\
\text { testv }_{i}=\text { testv }_{i-1}+1 \mathrm{~min}
\end{array}
$$

$d_{i}$ is the crossed distance by $A_{i}$; To make the set of data more accurate, we proceed by updating the position of each aircraft $A_{i}$. 


\subsection{Algorithm}

1 Compute test $_{i}$ for $i=1, \ldots, n$

2 Compute $t v_{i}$ using $a_{i}$ minimizing (7) for $i=1, \ldots, n$

3 Compute the delay/profit $R v_{i}$ for $i=1, \ldots, n$

\subsection{Application}

for $n=22$ :

- Compute the time to reach the hotspot $H$ for each $A_{i}$ with stored speed $V_{i}$;

- Initially, we chose the increasing order of activation time as a reference order;

- Compute the delay according to (FCFS) as shown in Table 4;

- Establish a new permutation increasing order of estimation time to reach the hotspot $H$;

- Apply the change on taxiing speed value;

- Compute $R v_{i}$ for each $A_{i}$ according to the taxiing speed adjustments (TSA) method as shown in Table 5:

$R v_{i}$ is the delay of aircraft $A_{i}$

Stand distance : Stdst

Type of aircraft: Tp

Activation time: Act

Time to clear the HotSpot: $\mathrm{Cl} \mathrm{Hpt}$

Authorized Time to enter the HotSpot: Aut Hpt

New Time to clear the HotSpot: $\mathrm{Nw} \mathrm{Cl} \mathrm{Hpt}$

Table 4. results using FCFS

\begin{tabular}{|c|c|c|c|c|c|c|c|}
\hline A & Stdst & Tp & Act & Cl Hpt & Aut Hpt & Nw Cl Hpt & $R v_{i}$ \\
\hline 1 & 9 & 6 & 1 & 184 & 163 & 184 & 0 \\
\hline 2 & 6 & 5 & 1,4 & 109,4 & 184 & 202 & 92,6 \\
\hline 3 & 8 & 6 & 2,3 & 167,3 & 202 & 223 & 55,7 \\
\hline 4 & 9 & 4 & 3,8 & 126,8 & 223 & 238 & 111,2 \\
\hline 5 & 6 & 6 & 4 & 133 & 238 & 259 & 126 \\
\hline 6 & 8 & 5 & 5,2 & 143,2 & 259 & 277 & 133,8 \\
\hline 7 & 5 & 4 & 6,4 & 81,4 & 277 & 292 & 210,6 \\
\hline 8 & 8 & 3 & 6,6 & 90,6 & 292 & 304 & 213,4 \\
\hline 9 & 7 & 4 & 7,8 & 106,8 & 304 & 319 & 212,2 \\
\hline 10 & 6 & 5 & 9 & 117 & 319 & 337 & 220 \\
\hline 11 & 8 & 3 & 10,2 & 94,2 & 337 & 349 & 254,8 \\
\hline 12 & 7 & 4 & 11,4 & 110,4 & 349 & 364 & 253,6 \\
\hline 13 & 6 & 3 & 12,6 & 78,6 & 364 & 376 & 297,4 \\
\hline 14 & 4 & 4 & 13,8 & 76,8 & 376 & 391 & 314,2 \\
\hline 15 & 5 & 2 & 14 & 53 & 391 & 400 & 347 \\
\hline 16 & 4 & 5 & 15,2 & 93,2 & 400 & 418 & 324,8 \\
\hline 17 & 5 & 4 & 16,4 & 91,4 & 418 & 433 & 341,6 \\
\hline 18 & 4 & 2 & 17,6 & 50,6 & 433 & 442 & 391,4 \\
\hline 19 & 5 & 3 & 17,8 & 74,8 & 442 & 454 & 379,2 \\
\hline 20 & 6 & 1 & 18 & 42 & 454 & 460 & 418 \\
\hline 21 & 4 & 2 & 20,2 & 53,2 & 460 & 469 & 415,8 \\
\hline 22 & 3 & 1 & 21,4 & 36,4 & 469 & 475 & 438,6 \\
\hline & $\ldots$ & $\ldots$ & $\ldots$ & $\ldots$ & $\ldots$ & Second & 5552 \\
\hline
\end{tabular}


Table 5. results using TSA

\begin{tabular}{|c|c|c|c|c|c|c|c|c|}
\hline P & Stdst & Tp & Act & Rt Reg & Cl Hpt & Aut Hpt & Nw Cl Hpt & $R v_{i}$ \\
\hline 22 & 3 & 1 & 21,4 & 0,8 & 35,8 & 24,32 & 29,72 & 0 \\
\hline 20 & 6 & 1 & 18 & 0,825 & 41,475 & 29,72 & 35,195 & 0,02 \\
\hline 18 & 4 & 2 & 17,6 & 0,8455 & 50,136 & 35,19 & 43,7315 & 0,02 \\
\hline 15 & 5 & 2 & 14 & 0,99 & 52,98 & 43,73 & 52,71 & 0 \\
\hline 21 & 4 & 2 & 20,2 & 1,1924 & 53,78 & 52,71 & 62,29 & 0,01 \\
\hline 14 & 4 & 4 & 13,8 & 1,08 & 76,82 & 62,29 & 77,31 & 0,002 \\
\hline 19 & 5 & 3 & 17,8 & 1,2 & 75,4 & 77,31 & 89,91 & 1,95 \\
\hline 7 & 5 & 4 & 6,4 & 1,2 & 82 & 89,91 & 105,5 & 10,2 \\
\hline 13 & 6 & 3 & 12,6 & 1,2 & 79,2 & 105,5 & 118,1 & 25,6 \\
\hline 16 & 4 & 5 & 15,2 & 1,2 & 93,8 & 118,1 & 136,7 & 27,87 \\
\hline 17 & 5 & 4 & 16,4 & 1,2 & 92 & 136,7 & 152,3 & 45,03 \\
\hline 8 & 8 & 3 & 6,6 & 1,2 & 91,2 & 152,3 & 164,9 & 57,99 \\
\hline 11 & 8 & 3 & 10,2 & 1,2 & 94,8 & 164,9 & 177,5 & 66,27 \\
\hline 2 & 6 & 5 & 1,4 & 1,2 & 110 & 177,5 & 196,1 & 67,83 \\
\hline 9 & 7 & 4 & 7,8 & 1,2 & 107,4 & 196,1 & 211,7 & 85,95 \\
\hline 12 & 7 & 4 & 11,4 & 1,2 & 111 & 211,7 & 227,3 & 97,23 \\
\hline 10 & 6 & 5 & 9 & 1,2 & 117,6 & 227,3 & 245,9 & 108,51 \\
\hline 4 & 9 & 4 & 3,8 & 1,2 & 127,4 & 245,9 & 261,5 & 111,75 \\
\hline 5 & 6 & 6 & 4 & 1,2 & 133,6 & 261,5 & 283,1 & 127,11 \\
\hline 6 & 8 & 5 & 5,2 & 1,2 & 143,8 & 283,1 & 301,7 & 132,87 \\
\hline 3 & 8 & 6 & 2,3 & 1,2 & 167,9 & 301,7 & 323,3 & 126,15 \\
\hline 1 & 9 & 6 & 1 & 1,2 & 184,6 & 323,3 & 344,9 & 127,71 \\
\hline & & & & & & & Second & 1220,16 \\
& & & & & & & Min & 20,336 \\
\hline
\end{tabular}

Rate of Regulation : Rt Reg

\subsection{Comparative study}

The sum of accumulated delays by the 22 aircraft using FCFS sequencing processes is: $\mathrm{Rf}=5551,9$ seconds $(92,5316667 \mathrm{~min})$ shown in Tab 4. And the sum of the delays accumulated using the proposed sequencing processes (TSA) is: $\mathrm{Rn}=1220,2$ seconds: (20,34 $\mathrm{min})$ shown in Tab 5. The Profit by applying the new method is 72,19 min. According to the simulations appearing in Fig 5, the new algorithm with taxiing speed adjustments TSA provides outstanding results compared to FCFS.

\subsection{Fuel consumption}

Aircraft could delay starting their engines in the stand to save fuel. Once the aircraft start taxiing according to the speed profile in Figure 3 showing that Each segment is divided into four parts, corresponding to four different aircraft taxiing phases (acceleration, traveling at a constant speed, braking and braking with maximum deceleration) with a typical taxiing behavior. [30] Described a heuristic employed to find optimized speed profiles related to Fuel consumption reached by applying the "CTxT" which maintains the traveling at constant speed phase for a longer period. 


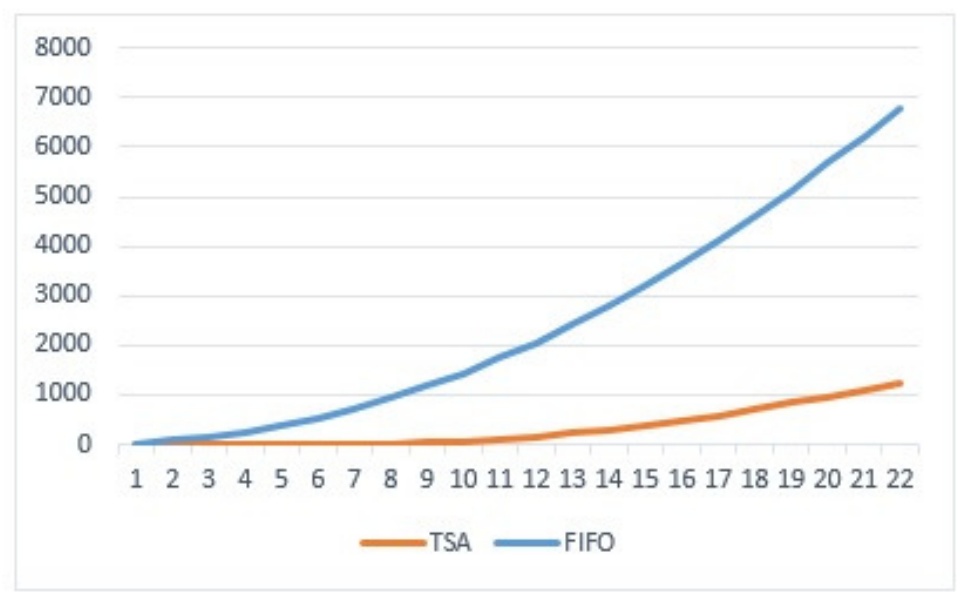

Figure 5. The delays accumulated by the 22 aircraft.

\section{Conclusion and further development}

On one hand the use of the proposed method has given remarkable improvements in terms of minimizing:taxiing time, air traffic controller workload, rapid acceleration, the burned fuel while waiting at hot spots, and excessive greenhouse gas emissions. On the other one, it allows the aircraft to maintain a constant speed as long as possible during the taxiing phase, which makes it possible to predict more accurately the taxiing time and the exact estimates of passing through conflict points and therefore ease the application of other optimization methods towards optimal use of the ground system at airports.

This contribution aims to facilitate the mission and reduce the workload of air traffic controllers with a decisionmaking support that increase the capacity of Air Traffic Management systems while ensuring a high level of safety. This tool (using real-time algorithms) will also reduce costs by acting on the taxiing speed during ground movement phases to reach an optimal air network management.

Our proposed work calculated the taxi out of the block time CTxT and taxiing speed adjustments TSA which provided outstanding results and benefits. It leads to an optimization of time, taxiing distances, fuel consumption, and green gaze emissions. Decrease the uncertainty of taxi time remains an important factor among others that could be introduced in further work, such as respecting allocated time slots, priority management and consideration of arriving operations.

\section{REFERENCES}

1. eurocontrol, "traffic growth 2018," eurocontrol, 2019, https://www.eurocontrol.int.

2. iata, "transportation growth," iata, 2019, https://www.iata.org/en/pressroom/pr/2017-10-24-01/.

3. T. Zhang, M. Ding, B. Wang, and Q. Chen, "Conflict-free time-based trajectory planning for aircraft taxi automation with refined taxiway modeling," Journal of Advanced Transportation, vol. 50, no. 3, pp. 326-347, 2016.

4. H. Khadilkar and H. Balakrishnan, "Network congestion control of airport surface operations," Journal of Guidance, Control, and Dynamics, vol. 37, no. 3, pp. 933-940, 2014.

5. L. Yang, S. Yin, K. Han, J. Haddad, and M. Hu, "Fundamental diagrams of airport surface traffic: Models and applications," Transportation research part B: Methodological, vol. 106, pp. 29-51, 2017.

6. J. Ma, D. Delahaye, M. Sbihi, and M. Mongeau, "Integrated optimization of terminal manoeuvring area and airport," 6th SESAR Innovation Days, 2016.

7. C. Yu, D. Zhang, and H. H. Lau, "A heuristic approach for solving an integrated gate reassignment and taxi scheduling problem," Journal of Air Transport Management, vol. 62, pp. 189-196, 2017.

8. O. E. Guclu and C. Cetek, "Analysis of aircraft ground traffic flow and gate utilisation using a hybrid dynamic gate and taxiway assignment algorithm," The Aeronautical Journal, vol. 121, no. 1240, pp. 721-745, 2017. 
9. J.-B. Gotteland, N. Durand, J.-M. Alliot, and E. Page, "Aircraft ground traffic optimization," in ATM 2001, 4th USA/Europe Air Traffic Management Research and Development Seminar, 2001, pp. pp-xxxx.

10. J.-B. Gotteland and N. Durand, "Genetic algorithms applied to airport ground traffic optimization," in The 2003 Congress on Evolutionary Computation, 2003. CEC'03., vol. 1. IEEE, 2003, pp. 544-551.

11. C. Stergianos, J. Atkin, P. Schittekat, T. E. Nordlander, C. Gerada, and H. Morvan, "The importance of considering pushback time and arrivals when routing departures on the ground at airports," in 8th international conference on applied operational research (ICAOR 2016), Rotterdam, The Netherlands, 2016, pp. 41-46.

12. S. Ravizza, J. A. Atkin, and E. K. Burke, "A more realistic approach for airport ground movement optimisation with stand holding," Journal of Scheduling, vol. 17, no. 5, pp. 507-520, 2014.

13. K. Yin, C. Tian, B. X. Wang, and L. Quadrifoglio, "Analysis of taxiway aircraft traffic at george bush intercontinental airport, houston, texas," Transportation research record, vol. 2266, no. 1, pp. 85-94, 2012.

14. G. Clare and A. G. Richards, "Optimization of taxiway routing and runway scheduling," IEEE Transactions on Intelligent Transportation Systems, vol. 12, no. 4, pp. 1000-1013, 2011.

15. J. Guépet, O. Briant, J.-P. Gayon, and R. Acuna-Agost, "The aircraft ground routing problem: Analysis of industry punctuality indicators in a sustainable perspective," European Journal of Operational Research, vol. 248, no. 3, pp. 827-839, 2016.

16. C. Evertse and H. Visser, "Real-time airport surface movement planning: Minimizing aircraft emissions," Transportation Research Part C: Emerging Technologies, vol. 79, pp. 224-241, 2017.

17. S. Ravizza, J. Chen, J. A. Atkin, P. Stewart, and E. K. Burke, "Aircraft taxi time prediction: comparisons and insights," Applied Soft Computing, vol. 14, pp. 397-406, 2014.

18. H. Khadilkar and H. Balakrishnan, "Integrated control of airport and terminal airspace operations," IEEE Transactions on Control Systems Technology, vol. 24, no. 1, pp. 216-225, 2015.

19. T. V. Truong, "The distribution function of airport taxi-out times and selected applications," in Journal of the Transportation Research Forum, vol. 50, no. 2, 2012.

20. I. Simaiakis and H. Balakrishnan, "A queuing model of the airport departure process," Transportation Science, vol. 50, no. 1, pp. 94-109, 2016.

21. O. Lordan, J. M. Sallan, and M. Valenzuela-Arroyo, "Forecasting of taxi times: The case of barcelona-el prat airport," Journal of Air Transport Management, vol. 56, pp. 118-122, 2016.

22. J. Koeners and R. Rademaker, "Creating a simulation environment to analyze benefits of real-time taxi flow optimization using actual data," in AIAA Modeling and Simulation Technologies Conference, 2011, p. 6372.

23. Y. Liu, M. Hansen, G. Gupta, W. Malik, and Y. Jung, "Predictability impacts of airport surface automation," Transportation Research Part C: Emerging Technologies, vol. 44, pp. 128-145, 2014.

24. H. Lee and H. Balakrishnan, "Fast-time simulations of detroit airport operations for evaluating performance in the presence of uncertainties," in 2012 IEEE/AIAA 31st Digital Avionics Systems Conference (DASC). IEEE, 2012, pp. 4E2-1.

25. T. K. Simić and O. Babić, "Airport traffic complexity and environment efficiency metrics for evaluation of atm measures," Journal of Air Transport Management, vol. 42, pp. 260-271, 2015.

26. D. Rappaport, P. Yu, K. Griffin, and C. Daviau, "Quantitative analysis of uncertainty in airport surface operations," in 9th AIAA Aviation Technology, Integration, and Operations Conference (ATIO) and Aircraft Noise and Emissions Reduction Symposium (ANERS), 2009, p. 6987.

27. A. E. Brownlee, M. Weiszer, J. Chen, S. Ravizza, J. R. Woodward, and E. K. Burke, "A fuzzy approach to addressing uncertainty in airport ground movement optimisation," Transportation Research Part C: Emerging Technologies, vol. 92, pp. 150-175, 2018.

28. C. Lesire, "Iterative planning of airport ground movements," in Proceedings of the 4th international conference on research in air transportation (ICRAT 2010), Budapest, Hungary, 2010, pp. 147-154.

29. J. Chen, S. Ravizza, J. A. Atkin, and P. Stewart, "On the utilisation of fuzzy rule-based systems for taxi time estimations at airports," in 11th Workshop on Algorithmic Approaches for Transportation Modelling, Optimization, and Systems. Schloss Dagstuhl-LeibnizZentrum fuer Informatik, 2011.

30. M. Weiszer, J. Chen, S. Ravizza, J. Atkin, and P. Stewart, "A heuristic approach to greener airport ground movement," in 2014 IEEE congress on evolutionary computation (CEC). IEEE, 2014, pp. 3280-3286. 